Swarthmore College

Works

$11-1-2003$

\title{
Djungarian Hamsters Exhibit Temperature-Dependent Dietary Fat Choice In Long Days
}

Sara Hiebert Burch

Swarthmore College, shieber1@swarthmore.edu

Kelley Carl Hauser , '99

Abbas Ebrahim , '00

Follow this and additional works at: https://works.swarthmore.edu/fac-biology

Part of the Biology Commons

Let us know how access to these works benefits you

\section{Recommended Citation}

Sara Hiebert Burch; Kelley Carl Hauser , '99; and Abbas Ebrahim , '00. (2003). "Djungarian Hamsters Exhibit Temperature-Dependent Dietary Fat Choice In Long Days". Physiological And Biochemical Zoology. Volume 76, Issue 6. 850-857. DOI: 10.1086/378142

https://works.swarthmore.edu/fac-biology/4

This work is brought to you for free by Swarthmore College Libraries' Works. It has been accepted for inclusion in Biology Faculty Works by an authorized administrator of Works. For more information, please contact myworks@swarthmore.edu. 


\section{CHICAGO JOURNALS}

Djungarian Hamsters Exhibit Temperature-Dependent Dietary Fat Choice in Long Days

Author(s): Sara M. Hiebert, Kelley Hauser, and Abbas J. Ebrahim

Source: Physiological and Biochemical Zoology, Vol. 76, No. 6 (November/December 2003), pp.

850-857

Published by: The University of Chicago Press

Stable URL: http://www.jstor.org/stable/10.1086/378142

Accessed: 05/03/2014 14:46

Your use of the JSTOR archive indicates your acceptance of the Terms \& Conditions of Use, available at

http://www.jstor.org/page/info/about/policies/terms.jsp

JSTOR is a not-for-profit service that helps scholars, researchers, and students discover, use, and build upon a wide range of content in a trusted digital archive. We use information technology and tools to increase productivity and facilitate new forms of scholarship. For more information about JSTOR, please contact support@jstor.org. 


\section{Djungarian Hamsters Exhibit Temperature-Dependent Dietary Fat Choice in Long Days}

\author{
Sara M. Hiebert ${ }^{\star}$ \\ Kelley Hauser \\ Abbas J. Ebrahim \\ Department of Biology, Swarthmore College, Swarthmore, \\ Pennsylvania 19081-1390
}

Accepted 6/5/03

\begin{abstract}
Previous studies have shown that whole-animal thermal responses of ectotherms and heterotherms (e.g., hibernators), both of which experience a wide range of body temperatures, are related to the saturation level of somatic lipids, which in turn can be influenced by the ratio of saturated and unsaturated fatty acids in the diet. This study demonstrates that Djungarian hamsters held in long days display ambient temperaturedependent choice of dietary fats, increasing their preference for saturated fats when ambient temperature increases (to $27^{\circ} \mathrm{C}$ ) and later reversing this preference when ambient temperature is returned to its original value $\left(8^{\circ} \mathrm{C}\right)$. Changes in percent contribution of the unsaturated and saturated diets in response to temperature were accomplished almost solely by changes in the amount of unsaturated diet consumed. Temperature-dependent fatty acid choice occurs at a stage in the annual cycle when Djungarian hamsters do not enter spontaneous daily torpor and therefore experience only small changes in core body temperature. These results suggest that temperature-dependent fatty acid choice may occur in a wide range of animals, including nonheterothermic endotherms.
\end{abstract}

\section{Introduction}

Acclimatization to changes in environmental temperature includes changes in the composition of somatic fatty acids, both in fat depots and in cell membranes. Cold-adapted tissues typically contain a higher proportion of unsaturated fatty acids than those functioning at higher temperatures (e.g., Irving et al. 1957; Williams 1998). The desaturation of tissue lipids is

\footnotetext{
*Corresponding author; e-mail: shieber1@swarthmore.edu.
}

Physiological and Biochemical Zoology 76(6):850-857. 2003. (C) 2003 by The University of Chicago. All rights reserved. 1522-2152/2003/7606-2002\$15.00 believed to assist in counteracting the crystallizing effects of decreasing temperature and thus plays an important role in the homeoviscous adaptation of cell membranes and in maintaining the fluidity of depot fats to allow their mobilization as a fuel source (Mead et al. 1986; Hazel 1995, 1997).

Previous studies have demonstrated that a wide variety of mammals entering torpor daily or seasonally (daily heterotherms and hibernators, respectively) do so more frequently, for longer periods of time and at lower body temperatures, when they have been fed a diet rich in unsaturated fatty acids than when they have been fed a diet rich in saturated fatty acids (Geiser and Kenagy 1987; Geiser 1990, 1993; Frank 1992; Florant et al. 1993; Thorp et al. 1994). When they are given a choice between simultaneously offered diets rich in saturated and unsaturated fatty acids, respectively, golden-mantled ground squirrels (Spermophilus lateralis) preparing for hibernation have a preference for diets rich in unsaturated fatty acids (Frank 1994; but see also Frank et al. 1998). Similarly, Djungarian hamsters (Phodopus sungorus), which are daily heterotherms, exhibit a temperature-dependent fatty acid preference when they are exposed to short days, as would be experienced in the winter; they choose to consume significantly higher proportions of the diet rich in unsaturated fatty acids when they are exposed to a cold environment than when they are exposed to a warm environment (Hiebert et al. 2000). Geiser and Heldmaier (1995) have shown that in Phodopus, as in other mammals (Mead et al. 1986; Gunstone 1996), changes in the saturation level of dietary fatty acids are subsequently reflected in the fatty acid composition of somatic tissues, supporting the hypothesis that dietary fat choice affects the performance of fat-containing tissues.

In both diet choice studies reported thus far, animals were tested under seasonal conditions associated with torpor or preparation for seasonal torpor. In late summer, when the study on ground squirrels was conducted, these animals are stimulated to fatten for hibernation by an endogenous circannual clock (Pengelley and Asmundson 1974; Zucker 2001). Djungarian hamsters, however, remain perpetually in summer condition unless exposed to short days (Goldman and Elliot 1988), which provide the proximate cue that stimulates a suite of changes that prepare the animals for winter: lightening of the fur, increase in fur thickness, regression of the gonads, decrease in body mass, and onset of spontaneous daily torpor (Heldmaier and Steinlechner 1981; Bartness et al. 1989). Although their study did not specifically consider dietary fatty acid composition, Fine and Bartness (1996) have demonstrated that the 
day length to which $P$. sungorus are exposed can stimulate changes in diet preference. Together, these findings raise a new question: Is exposure to short days necessary for the expression of temperature-dependent dietary fat choice, or are changes in ambient temperature sufficient to elicit changes in dietary choice behavior, regardless of day length? To answer this question, we investigated dietary fat choice in Djungarian hamsters using a protocol similar to that of Hiebert et al. (2000), except that in this study animals had been exposed continuously to a long-day photoperiod and were therefore in summer physiological condition. If long-day hamsters were found to exhibit temperature-dependent dietary fat preference, we wished further to compare the time course of changes in dietary fat preference in long and short days to determine whether photoperiod influences the responsiveness of hamsters to ambient temperature changes in more subtle ways. Our hypothesis was that short-day hamsters might respond to changes in ambient temperatures more rapidly than long-day hamsters, which would be far less likely to experience large changes in ambient or core body temperature and might therefore have a reduced need to adjust the saturation level of somatic fats.

\section{Material and Methods}

Animals

Male and female hamsters $(N=25)$ approximately 20 mo old were kept from birth at $21^{\circ} \pm 1^{\circ} \mathrm{C}$ in long days $(16 \mathrm{~L}: 8 \mathrm{D}$ for the first $10 \mathrm{mo}$ and $14 \mathrm{~L}: 10 \mathrm{D}$ thereafter). Throughout the experiment, animals continued to be maintained on $14 \mathrm{~L}: 10 \mathrm{D}$ in individual plastic cages $(18 \mathrm{~cm} \times 28 \mathrm{~cm} \times 13 \mathrm{~cm})$ lined with pine shavings and were provided with water ad lib. All hamsters were provided with extra cotton bedding for insulation.

\section{Diets}

The two diets, hereafter referred to as the saturated and unsaturated diets, were made by marinating pellets of Purina 5001 chow $(4.5 \%$ crude fat) in sufficient beef fat or sunflower oil, respectively, to result in a $10 \%$ addition of mass (for details, see Hiebert et al. 2000; for composition, see Table 1). Food was stored at $4^{\circ} \mathrm{C}$ until use. The food hopper in each cage was separated into two sections by a wire-mesh divider, one for each diet. Each animal always received the unsaturated diet on the same side of the divider, but half of the animals were randomly assigned to receive the unsaturated diet on the left side of the hopper, while the remaining animals received the unsaturated diet on the right side. Food remaining in the hopper was weighed daily to determine the quantity eaten. Each hamster always had access to sufficient quantities of each diet, so its daily nutritional and energetic needs could be met by consuming only one of the diets.
Table 1: Fatty acid composition of sunflower oil and beef fat (wt \%)

\begin{tabular}{lcc}
\hline & ${\text { Sunflower } \text { Oil }^{\mathrm{a}}}$ & Beef Fat $^{\mathrm{b}}$ \\
\hline Saturated fatty acids & 14.3 & 53.3 \\
Monounsaturated fatty acids & 21.4 & 40.6 \\
Polyunsaturated fatty acids & 64.3 & 6.1 \\
\hline
\end{tabular}

a Manufacturer's analysis.

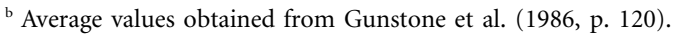

\section{Experiment Time Line}

The experiment was divided into three phases (Fig. 1). During phase I (which lasted $10 \mathrm{~d}$ ), all hamsters were held in a walkin environmental chamber at $8^{\circ} \mathrm{C}$. Hamsters were then divided into control $(N=12)$ and experimental $(N=13)$ groups of similar body mass and percent unsaturated diet consumption, averaged over all days of phase I. During phase II (which lasted $24 \mathrm{~d}$ ), control hamsters remained in the environmental chamber at $8^{\circ} \mathrm{C}$, while the experimental hamsters were housed in a light-tight cabinet at $27^{\circ} \pm 1^{\circ} \mathrm{C}$. During phase III (which lasted $15 \mathrm{~d}$ ), experimental hamsters were again housed in the $8^{\circ} \mathrm{C}$ environmental chamber with the control hamsters. Transitions between temperature treatments (Fig. $2 a$ ) were made over several days because previous experience suggested that large, abrupt temperature changes may pose a health risk to the animals. Because only one cold chamber was available, both treatment groups underwent some changes in ambient temperature during each transition. All animals were weighed at the beginning of each phase of the experiment.

\section{Data Analysis and Statistics}

The effect of ambient temperature on diet preference was determined by comparing mean percent unsaturated diet consumption between the two treatment groups during phases II and III, with a Bonferroni correction for the use of multiple $t$-tests $(\alpha$ was set at $0.05 / 2=0.025$ ). Phase I was not included in this analysis because treatment groups had been constructed in such a way as to eliminate any differences in percent unsaturated diet consumption between treatment groups during phase I. Five-day moving averages of mean percent unsaturated diet consumption during phases II and III of long-day (this study) and short-day hamsters (data reanalyzed from Hiebert et al. 2000) were used to compare the patterns of change in diet preference in summer- and winter-adapted hamsters, respectively. During phase II, the only phase in which $P$ values were lower than $0.05, \alpha$ was set at $0.05 / 8=0.00375$ to compensate for multiple comparisons.

We compared the total amount of each diet consumed by controls with that consumed by experimentals in each of the three phases of the experiment, with two sets of three MannWhitney $U$-tests-one set for each diet. The nonparametric 


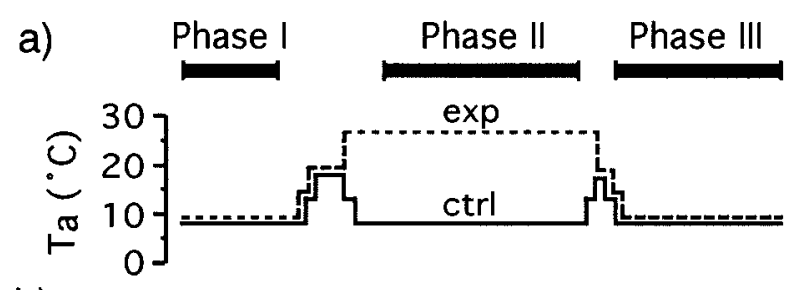

b)

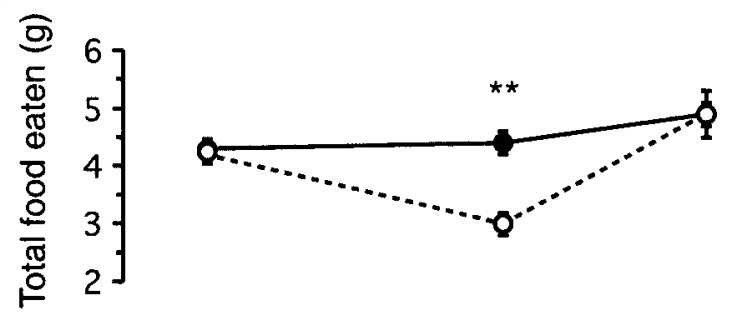

c)

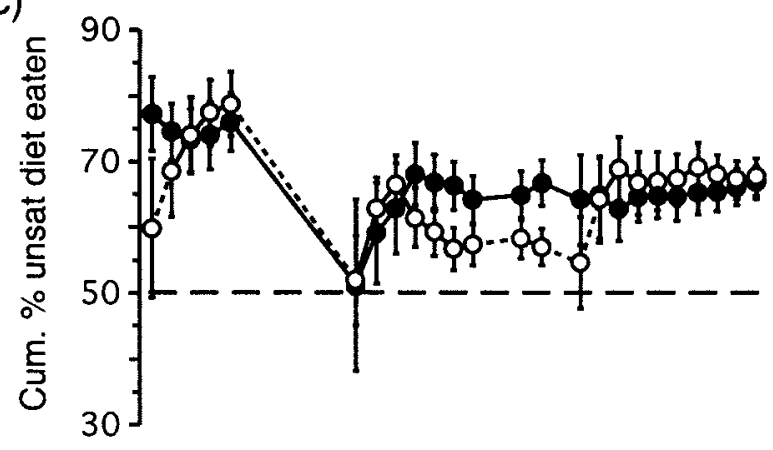

d)

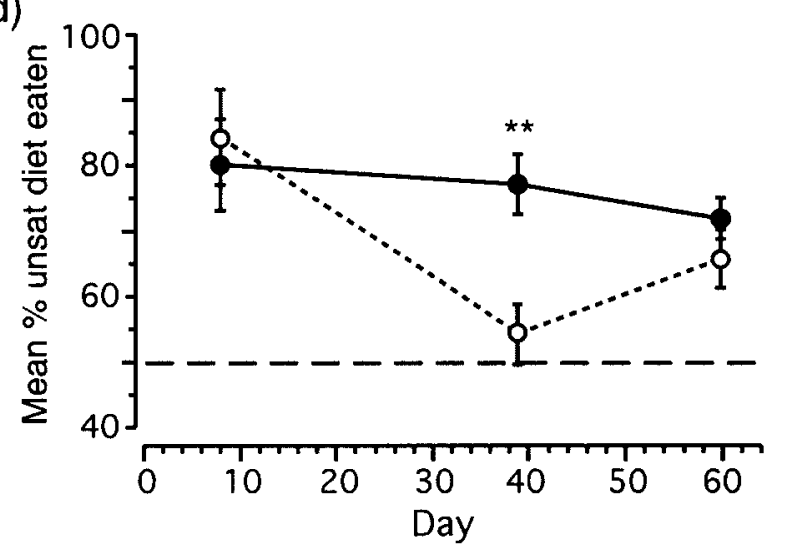

Figure 1. Effect of ambient temperature on food consumption and dietary fat choice. a, Experimental (dotted lines) and control (solid lines) hamsters were held at $8^{\circ} \mathrm{C}$ during the experiment except for the experimental group during phase II. Ambient temperature was changed in increments of $3^{\circ}-5^{\circ} \mathrm{C}$ per day at the beginning of the experiment and between phases to allow animals to adjust to changes gradually. Except between days 17 and 43, dotted and solid lines are separated from each other only for visual clarity; the temperatures experienced

Mann-Whitney $U$-test was used because several of the samples were either nonnormally distributed or exhibited significantly heterogeneous variances. Phase I was included in this analysis because treatment groups had been balanced for percent unsaturated diet consumed but not for absolute amount of each diet consumed. A Bonferroni correction was applied to correct for the use of multiple Mann-Whitney $U$-tests ( $\alpha$ was set at $0.05 / 3=0.017$ ). Data from Hiebert et al. (2000) were reanalyzed by the same method.

Absolute preference for the unsaturated versus saturated diets was determined using a one-sample $t$-test to compare percent of unsaturated diet consumed with $50 \%$, the value that would result if the two diets were equally preferred.

For visual clarity of overall patterns of food consumption over the course of each phase, data within each phase are plotted as cumulative means. These plots are conservative indices of change over time because points at the end of a phase are moderated by averaging with all other points in that phase.

\section{Results}

Body mass decreased significantly from the beginning of phase I $(36.7 \pm 1.3 \mathrm{~g})$ to the beginning of phase II $(33.4 \pm 0.8 \mathrm{~g}$; paired $t$-test, $P<0.0001$ ), during the time when all hamsters were initially adjusting to the cold environment. Mass loss during phase I was directly correlated with body mass at the beginning of phase I $\left(R^{2}=0.64, P<0.0001\right)$; that is, fat hamsters lost more mass during phase I than lean hamsters (data not shown).

by the two treatment groups during the remainder of the experiment were identical. $b$, Total food consumption, shown as the mean from the last $5 \mathrm{~d}$ of each phase, was indistinguishable between the experimental (open circles) and control (filled circles) treatment groups during phases I and III but significantly lower in the experimental group during phase II $(P=0.001) . c$, Percent unsaturated diet consumption for experimental and control hamsters. Each point represents the cumulative mean of all animals' mean unsaturated diet consumption, averaged over all days from the beginning of that phase to the day on which the point appears. For visual clarity, only data from every other day are included. During phases I and III, percent unsaturated diet consumption was indistinguishable between control and experimental treatment groups, but during phase II, a significant difference developed over time and was maintained until experimental animals were returned to $8^{\circ} \mathrm{C}$ at the beginning of phase III. Horizontal dashed line represents equal preference for both diets. $d$, Mean percent unsaturated diet eaten over the last $5 \mathrm{~d}$ of each phase, representing the ultimate effect of each treatment phase, shows indistinguishable differences between experimentals and controls when animals were held at $8^{\circ} \mathrm{C}$, but experimental hamsters significantly reduced the percentage of unsaturated diet consumption in comparison with controls when they were moved to $27^{\circ} \mathrm{C}$ ( two asterisks, $P=0.002$ ). Horizontal dashed line represents equal preference for both diets. All data are shown as mean \pm SEM. 
a) LONG DAYS (LD 14:10)
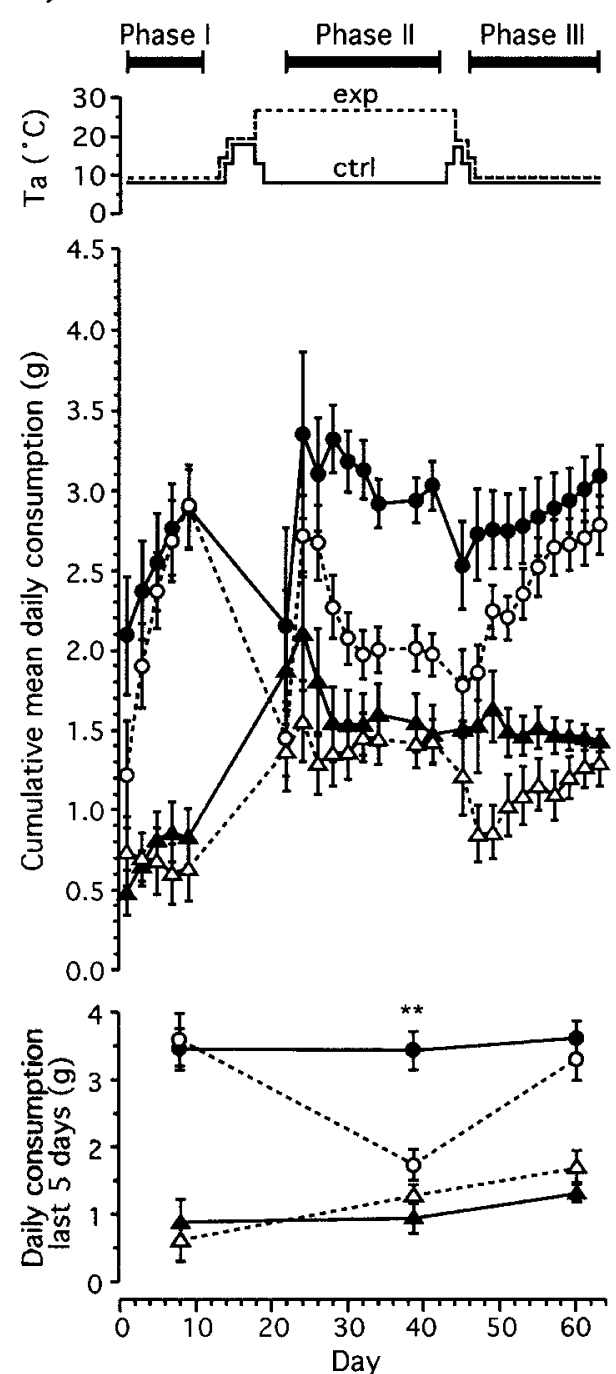

b) SHORT DAYS (LD 8:16)
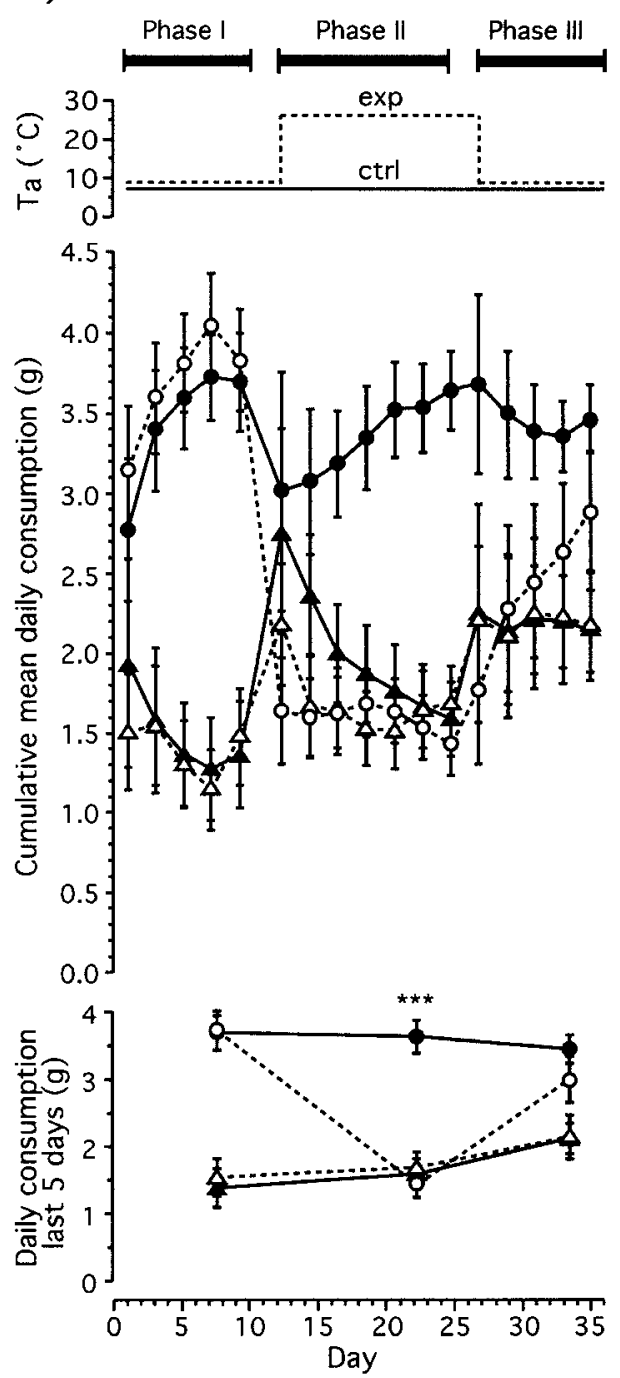

Controls $\left\{\begin{array}{l}\text { unsaturated diet } \\ \text { saturated diet }\end{array}\right.$ Experimentals $\left\{\begin{array}{l}\text { unsaturated diet } 0 \\ \text { saturated diet } \Delta\end{array}\right.$

Figure 2. Change in absolute amount of saturated and unsaturated diet consumed by experimental and control hamsters during the three phases of the experiment in $(a)$ long days $(14 \mathrm{~L}: 10 \mathrm{D})$ and $(b)$ short days $(8 \mathrm{~L}: 16 \mathrm{D})$. Cumulative means: each point represents the cumulative mean of all animals' mean saturated or unsaturated diet consumption in each treatment group, averaged over all days from the beginning of that phase to the day on which the point appears. For visual clarity, only data from every other day are included. Daily consumption: average amount of each diet consumed per day during the last $5 \mathrm{~d}$ of each phase, representing the ultimate effect of each temperature treatment. Consumption of the saturated diet remained relatively stable throughout the experiment in both treatment groups, but consumption of unsaturated diet was significantly lower in experimental than in control hamsters during phase II (two asterisks, $P=0.002$ in long days; three asterisks, $P<0.0001$ in short days). All data are shown as mean \pm SEM.

Total food consumption was higher when hamsters were in the cold environment than when they were in the warm environment, which was expected because of the increased metabolic cost of thermoregulation in the cold (Fig. 1). Treatment groups had been chosen so that total food consumption was similar during phase I, but during the last $5 \mathrm{~d}$ of phase II, experimental hamsters consumed significantly less food $(3.0 \pm 0.2 \mathrm{~g} / \mathrm{d})$ than did the control hamsters $(4.3 \pm 0.2 \mathrm{~g} / \mathrm{d}$; Mann-Whitney $U$-test, $P=0.001)$. This difference disappeared during phase III (Mann-Whitney $U$-test, $P=0.6$; Fig. 1). 
Preference for the unsaturated diet, expressed as the percent of the diet composed of the unsaturated diet, was significantly affected by ambient temperature (Fig. 1). During the last $5 \mathrm{~d}$ of phase I, the unsaturated diet composed a similar proportion of the total diet in hamsters that would become the control group $(80.1 \% \pm 6.9 \%)$ and hamsters that would become the experimental group $(84.3 \% \pm 7.3 \%)$. In both treatment groups, hamsters significantly preferred the unsaturated diet over the saturated diet (one-sample $t$-test, $P<0.0001$ in both groups). Over the course of phase II, a difference in unsaturated diet preference developed between the experimental and control groups, first becoming evident on day 8 (Table 2). During the last $5 \mathrm{~d}$ of phase II, the experimental hamsters in the warm environment ate a significantly smaller proportion of the unsaturated diet $(54.3 \% \pm 4.6 \%)$ than did the control hamsters $(77.2 \% \pm 4.6 \%$; two-sample $t$-test, $P=0.002)$. When experimental hamsters were returned to the cold room in phase III, the difference in preference between the two treatment groups had already disappeared by day 5 (experimentals, $72.1 \% \pm$ $5.2 \%$ unsaturated diet vs. controls $64.5 \% \pm 5.1 \%$ unsaturated diet; Table 2; Fig. 1). This difference in means continued to decrease throughout phase III (Fig. 1; Table 2).

Daily consumption of saturated and unsaturated diets, when expressed simply as the mass of each diet consumed, showed a similar pattern in both long and short days (Fig. 2). Daily consumption of the saturated diet during the last $5 \mathrm{~d}$ of each phase, which may be taken as the cumulative effect of exposure to the conditions of each phase, was indistinguishable between control and experimental treatment groups in all phases in both short and long days $(P>0.05$ in all cases). Daily consumption of the unsaturated diet during the last $5 \mathrm{~d}$ of each phase was indistinguishable between control and experimental treatment groups in phases I and III when both treatment groups were exposed to the cold but significantly lower in experimentals than controls during phase II when only experimentals were exposed to the warm environment (short days, $P<0.0001$; long

Table 2: Time course for development of temperature-dependent dietary fat choice in short-day and long-day Djungarian hamsters (Phodopus sungorus)

\begin{tabular}{|c|c|c|c|c|}
\hline & \multicolumn{2}{|l|}{ Short Days $(8 \mathrm{~L}: 16 \mathrm{D})^{\mathrm{a}}$} & \multicolumn{2}{|l|}{ Long Days $(14 \mathrm{~L}: 10 \mathrm{D})^{\mathrm{b}}$} \\
\hline & Mean Difference $(\%)^{\mathrm{c}}$ & $P$ & Mean Difference $(\%)^{\mathrm{c}}$ & $P$ \\
\hline \multicolumn{5}{|l|}{ Phase II: $^{\mathrm{d}}$} \\
\hline Days $1-5$ & 10.6 & .23 & -2.9 & .72 \\
\hline Days 2-6 & 9.4 & .30 & 2.9 & .67 \\
\hline Days 3-7 & 13.3 & .18 & 10.7 & .14 \\
\hline Days $4-8$ & 12.9 & .20 & 13.6 & .03 \\
\hline Days 5-9 & 12.0 & .23 & 16.8 & .005 \\
\hline Days 6-10 & 20.3 & .03 & 21.3 & .004 \\
\hline Days 7-11 & 28.3 & $.002^{*}$ & 19.5 & $.003^{*}$ \\
\hline Days $8-12$ & 33.4 & $.0007^{\star}$ & 12.3 & .04 \\
\hline \multicolumn{5}{|l|}{ Phase III: ${ }^{e}$} \\
\hline Days $1-5$ & 9.9 & .99 & -7.6 & .31 \\
\hline Days 2-6 & 7.0 & .93 & -8.3 & .27 \\
\hline Days 3-7 & 7.5 & .78 & -6.9 & .31 \\
\hline Days $4-8$ & 9.6 & .25 & -4.8 & .50 \\
\hline Days 5-9 & 4.7 & .48 & -1.5 & .84 \\
\hline Days $6-10$ & 2.4 & .68 & -.2 & .97 \\
\hline
\end{tabular}

a Data for short days were reanalyzed from Hiebert et al. (2000).

${ }^{\mathrm{b}}$ Data for long days are from this study.

${ }^{c}$ Difference between mean percent unsaturated diet consumption of experimental and control hamsters over the 5 -d period indicated in column 1.

${ }^{\mathrm{d}}$ During phase II, experimental hamsters were exposed to $26^{\circ}-29^{\circ} \mathrm{C}$ (short days, $N=15$; long days, $N=13$ ), while control hamsters were held at $8^{\circ} \mathrm{C}$ (short days, $N=14$; long days, $N=12$ ). Data are shown only for those days of phase II for which there were data for both long and short days.

${ }^{\mathrm{e}}$ During phase III, both experimental (short days, $N=15$; long days, $N=11$ ) and control hamsters (short days, $N=14$; long days, $N=11$ ) were held at $8^{\circ} \mathrm{C}$. Data are shown only for those days of phase II for which there were data for both long and short days.

* Significant difference in dietary fatty acid choice between cold- and warm-exposed hamsters (Bonferroni-corrected $\alpha=0.00375)$. 
days, $P=0.002$ ).

The time course of changes in unsaturated diet preference in the two temperature-treatment groups showed similar patterns in short- and long-day hamsters, appearing within 7-11 $\mathrm{d}$ of exposure to different ambient temperatures in phase II and disappearing immediately when both treatment groups were again exposed to the same ambient temperatures in phase III (Table 2).

\section{Discussion}

Djungarian hamsters change their preference for dietary unsaturated fats in a temperature-dependent fashion not only in short days (Hiebert et al. 2000), when they would normally be expected to lower core body temperature during spontaneous daily torpor as a means of conserving energy, but also in long days, when core body temperature changes only minimally in response to changes in ambient temperature because the animals do not enter torpor (this study). The ability of hamsters to adjust to thermal challenges in this way seems to be a generalized response that neither requires seasonal preparation nor varies substantially in time course from season to season.

Although body temperature was not measured in this study, values should be similar to those observed in short-day hamsters that did not enter torpor when exposed to similar ambient temperatures (Hiebert et al. 2000). Previous studies have focused on the relation between dietary fats and whole-animal thermal responses in mammalian hibernators, reptiles, and other ectotherms (e.g., Geiser et al. 1992; Geiser and Learmonth 1994; Kashiwagi et al. 1997; Simandle et al. 2001), all of which may experience changes in body temperature in excess of $25^{\circ} \mathrm{C}$. This study supports the conclusion that smaller changes in ambient temperature $\left(19^{\circ} \mathrm{C}\right)$, which are accompanied by much smaller changes in average core body temperature of approximately $0.3^{\circ} \mathrm{C}$ (Hiebert et al. 2000), are sufficient to stimulate changes in dietary fat preference congruent with the known relation between temperature, fatty acid saturation, and storage lipid and/or membrane fluidity.

Many studies have focused on preferences for sensory features of fat such as texture and the odor and/or taste of impurities originating either in the natural source of the fats (sunflower or beef) or from oxidation during preparation (Ramirez 1992, 1993; Drewnowski 1997). In this study, the texture of the fat we added to the diet should be less salient than if it had been offered by itself because it constituted only $10 \%$ of the diet and during preparation was allowed to permeate the chow until the outside surface of the pellet appeared nearly dry. The difference in taste and odor of the two diets, identifiable even to us, undoubtedly arose in part from the impurities in sunflower oil and beef fat that we did not remove. However, changes in dietary fat preference over the course of this study cannot be attributed simply to an increasing preference for the taste of one of the diets over time because preferences were changed by increasing ambient temperature and later reversed when ambient temperature was returned to its original value.

A more plausible explanation for the basis of discrimination among dietary fats, consistent with the observation that the primary dietary adjustment in response to changes in ambient temperature was to the absolute quantity of unsaturated diet consumed, may lie in the recent discovery of gustatory mechanisms for detecting the essential polyunsaturated fatty acids in rats (reviewed in Gilbertson 1998). Undoubtedly, the ability to detect essential fatty acids is important for general survival (Gilbertson 1998). The study by Hiebert et al. (2000) and this study, together with a host of studies showing that the saturation level of dietary fats affect thermoregulation in ectotherms and heterotherms (see "Introduction"), now suggest a further role for essential fatty acid taste reception in promoting survival.

We note several caveats, however. First, evidence that rats prefer monounsaturated fatty acids but are indifferent to saturated fatty acids (Ramirez 1992) supports the idea that rodents may under certain conditions prefer unsaturated fatty acids but argues that taste reception for polyunsaturated fatty acids cannot completely explain this preference. Second, a lack of evidence for specific saturated fatty acid taste reception cannot be taken as proof that such reception does not exist.

Third, the relatively constant absolute contribution of the saturated diet ( $\mathrm{g}$ ) to total food consumption may be the result of regulation rather than the result of a lack of regulation or an inability to detect saturated fatty acids. In the kind of experiment reported here, we do not believe it is appropriate to conclude that when a preference for either diet is statistically indistinguishable from $50 \%$ the animals are necessarily eating at random (expressing no preference), as would typically be concluded in a two-bottle test for preference (e.g., Ramirez 1992). An approximately equal consumption of both diets, as was achieved by the experimental hamsters when they were moved to $28^{\circ} \mathrm{C}$ (Fig. $1 \mathrm{~d}$ ), is more plausibly interpreted as indicating that this diet provided the appropriate ratio of saturated and unsaturated fats at an ambient temperature of $28^{\circ} \mathrm{C}$. It is interesting to note that this temperature-appropriate ratio was achieved by decreasing the absolute amount of unsaturated fatty acids consumed. Such a response may be favored because unsaturated fatty acids, while affording benefits for membrane homeoviscosity at low body temperatures, also carry the costs of increased peroxidation and propagation of free radical chain reactions relative to saturated fatty acids (Gunstone 1996; Frank et al. 1998).

The ability to detect specific fatty acids does not by itself explain whether temperature-dependent fat preferences are innate or acquired, nor does it preclude detection of dietary fat composition by some postingestive mechanism (e.g., Honoré et al. 1994; Poirier et al. 1997; Lucas et al. 1998; Singer et al. 1999). Further investigations, in progress in our laboratory, are designed to answer some of these questions. 


\section{Acknowledgments}

We wish to acknowledge assistance from the following people: Tanyaporn Wansom, for help during the experiment; Matthew Powell and Jessica Robinson, for computer help; Hilary Clay and Clarissa Nobile, for graciously giving up the use of the environmental chamber; Cynthia Ristine and Rory Alarcon, for animal care; two anonymous reviewers, for their helpful comments and suggestions; and the Swarthmore College Biology Department, for funding this study. Animal care and experi mental methods used in these studies conform to the principles and guidelines set forth in the Guide to the Care and Use of Laboratory Animals and were authorized by protocols approved by the Swarthmore College Institutional Animal Care and Use Committee.

\section{Literature Cited}

Bartness T.J., J.A. Elliot, and B.D. Goldman. 1989. Control o torpor and body weight patterns by a seasonal timer in Siberian hamsters. Am J Physiol 257:R142-R149.

$\rightarrow$ Drewnowski A. 1997. Taste preferences and food intake. Annı $\rightarrow$ Rev Nutr 17:237-253.

$\rightarrow$ Fine J.B. and T.J. Bartness. 1996. Daylength and body mass affect diet self-selection by Siberian hamsters. Physiol Behar $\rightarrow$ 59:1039-1050.

Florant G.L., L. Hester, S. Ameenuddin, and D.A. Rintoul. 1993. The effect of a low essential fatty acid diet on hibernation $\rightarrow$ in marmots. Am J Physiol 264:R747-R753.

$\rightarrow$ Frank C.L. 1992. The influence of dietary fatty acids on hibernation by golden-mantled ground squirrels (Spermophilus lateralis). Physiol Zool 65:906-920.

$\rightarrow$. 1994. Polyunsaturate content and diet selection by ground squirrels (Spermophilus lateralis). Ecology 75:458463.

$\rightarrow$ Frank C.L., E.S. Dierenfeld, and K.B. Storey. 1998. The rela $\rightarrow$ tionship between lipid peroxidation, hibernation, and food selection in mammals. Am Zool 38:341-349.

$\rightarrow$ Geiser F. 1990. Influence of polyunsaturated and saturated dietary lipids on adipose tissue, brain, and mitochondrial membrane fatty acid composition of a mammalian hibernator. Biochim Biophys Acta 1046:159-166.

1993. Dietary lipids and thermal physiology. Pp. 141153 in C. Carey, G.L. Florant, B.A. Wunder, and B. Horwitz, eds. Life in the Cold: Ecological, Physiological and Molecular Mechanisms. Westview, Boulder, Colo.

Geiser F., B.T. Firth, and R.S. Seymour. 1992. Polyunsaturated dietary lipids lower the selected body temperature of a lizard. J Comp Physiol 162B:1-4.

Geiser F. and G. Heldmaier. 1995. The impact of dietary fats, photoperiod, temperature and season on morphological variables, torpor patterns, and brown adipose tissue fatty acid composition of hamsters, Phodopus sungorus. J Comp Physiol 165B:406-415.

Geiser F. and G.J. Kenagy. 1987. Polyunsaturated lipid diet lengthens torpor and reduces body temperature in a hibernator. Am J Physiol 252:R897-R901.

Geiser F. and R.P. Learmonth. 1994. Dietary fats, selected body temperature and tissue fatty acid composition of agamid lizards (Amphibolurus nuchalis). J Comp Physiol 164B:5561.

Gilbertson T.A. 1998. Gustatory mechanisms for the detection of fat. Curr Opin Neurobiol 8:447-452.

Goldman B.C. and J.A. Elliot. 1988. Photoperiodism and seasonality in hamsters: role of the pineal gland. Pp. 203-218 in M.H. Stetson, ed. Processing of Environmental Information in Vertebrates. Springer, New York.

Gunstone F.D. 1996. Fatty Acid and Lipid Chemistry. Blackie Academic and Professional, Glasgow.

Gunstone F.D., J.L. Harwood, and F.B. Padley. 1986. The Lipid Handbook. Chapman \& Hall, New York.

$\rightarrow$ Hazel J.R. 1995. Thermal adaptation in biological membranes: is homeoviscous adaptation the explanation? Annu Rev Physiol 57:19-42.

$\rightarrow$. 1997. Thermal adaptation in biological membranes: beyond homeoviscous adaptation. Adv Mol Cell Biol 19:57101.

Heldmaier G. and S. Steinlechner. 1981. Seasonal pattern and energetics of short daily torpor in the Djungarian hamster, Phodopus sungorus. Oecologia 48:265-270.

Hiebert S.M., E. Fulkerson, K. Lindermayer, and S. McClure. 2000. The effect of temperature on preference for dietary unsaturated fatty acids in the Djungarian hamster (Phodopus sungorus). Can J Zool 78:1361-1368.

$\rightarrow$ Honoré E., J. Barhanin, B. Attali, F. Lesage, and M. Lazdunski. 1994. External blockade of the major delayed-rectifier $\mathrm{K}^{+}$ channel (Kv1.5) by polyunsaturated fatty acids. Proc Natl Acad Sci USA 91:1937-1944.

Irving L., K. Schmidt-Nielsen, and N.S.B. Abrahamsen. 1957. On the melting points of animal fats in cold climates. Physiol Zool 30:93-105.

Kashiwagi T., V.B. Meyer-Rochow, K. Nishimura, and E. Eguchi. 1997. Fatty acid composition and ultrastructure of photoreceptive membranes in the crayfish Procambarus clarkii under conditions of thermal and photic stress. J Comp Physiol 167B:1-8.

Lucas F., K. Ackroff, and A. Sclafani. 1998. High-fat diet preference and overeating mediated by postingestive factors in rats. Am J Physiol 275:R1511-R1522.

Mead J.F., R. Alfin-Slater, D. Howton, and G. Popjak. 1986. Lipids: Chemistry, Biochemistry, and Nutrition. Plenum, New York.

Pengelley E.T. and S.J. Asmundson. 1974. Circannual rhythmicity in hibernating mammals. Pp. 95-160 in E.T. Pengelley, ed. Circannual Clocks. Academic Press, New York. 
Poirier H., I. Niot, P. Degrace, M.C. Monnot, A. Bernard, and P. Besnard. 1997. Fatty acid regulation of fatty acid-binding protein expression in the small intestine. Am J Physiol 273 G289-G295.

$\rightarrow$ Ramirez I. 1992. Chemoreception for fat: do rats sense triglycerides directly? Appetite 18:193-206.

. 1993. Role of olfaction in starch and oil preference. Am J Physiol 265:R1404-R1409.

$\rightarrow$ Simandle E.T., R.E. Espinoza, K.E. Nussear, and C.R. Tracy. 2001. Lizards, lipids, and dietary links to animal function. Physiol Biochem Zool 74:625-640.

$\rightarrow$ Singer L.K., D.A. York, H.R. Berthoud, and G.A. Bray. 1999.
Conditioned taste aversion produced by inhibitors of fatty acid oxidation in rats. Physiol Behav 68:175-179.

Thorp C.R., P.K. Ram, and G.L. Florant. 1994. Diet alters metabolic rate in the yellow-bellied marmot (Marmota flaviventris) during hibernation. Physiol Zool 67:1213-1229.

Williams E.E. 1998. Membrane lipids: what membrane physical properties are conserved during physiochemically-induced membrane restructuring? Am Zool 38:280-289.

Zucker I. 2001. Circannual rhythms: mammals. Pp. 511-528 in J. Takahashi, F.W. Turek, and R.Y. Moore, eds. Handbook of Behavioral Neurobiology: Circadian Clocks. Plenum, New York. 